\title{
The Possibilities of Reduction of Polychlorinated Dibenzo-P-Dioxins and Polychlorinated Dibenzofurans Emission
}

\author{
Grzegorz Wielgosiński \\ Faculty of Process and Environmental Engineering, Technical University of Lodz, Wolczanska 213, 90-924 Lodz, Poland \\ Correspondence should be addressed to Grzegorz Wielgosiński, wielgos@wipos.p.lodz.pl
}

Received 15 January 2010; Accepted 12 April 2010

Academic Editor: Josiane Nikiema

Copyright ( $) 2010$ Grzegorz Wielgosiński. This is an open access article distributed under the Creative Commons Attribution License, which permits unrestricted use, distribution, and reproduction in any medium, provided the original work is properly cited.

In the study the most important and known polychlorinated dibenzo-p-dioxins (PCDDs) and polychlorinated dibenzo-furans (PCDFs) emission sources are presented and known methods of reduction of dioxin emission to the atmosphere are discussed in detail. It is indicated that the most relevant emission source is a combustion process. The mechanism of dioxin formation in thermal processes is presented in brief. The author characterized primary methods of reduction of PCDDs/PCDFs emission encompassing the interference into the combustion process to minimize their formation and discussed known secondary methods aimed at their removal from the stream of waste gases. It was attempted to make a critical assessment of PCDD/Fs reduction methods described in literature.

\section{Introduction}

On 23 May, 2001 in Stockholm there was signed the Convention concerning persistent organic pollutants (POPs). The reason for the convention was the necessity to regulate the issues connected with the production and utilization of certain organic substances-the so-called persistent organic pollutants. The convention introduced relevant limitations in the production, application, export, and import of POPs, as well as strict requirements concerning the record and monitoring. One of the most important decisions of Convention was the commitment to the continuous minimization or the final elimination of the release of such substances as dioxins and furan (PCDD/Fs), hexachlorobenzene (HCB) (as a precursor of dioxin synthesis) as well as polychlorinated biphenyls (PCBs) — as compounds with similar toxicity to dioxins, to the environment This indicates the necessity of the implementation of the best available techniques (BAT) to the industrial practice in the following fields: waste incineration, paper-mills using chlorine for whitening, steel mills and copper, aluminum and zinc mills, refineries utilizing waste oils, crematories, power plants, and thermalelectric power plants as well as the other activities.
Polychlorinated dibenzo-p-dioxins and polychlorinated dibenzofurans are categorized as the so-called endocrine disrupters - the substances disturbing the activity of the endocrine system. Since 1970s PCDD/Fs have been thought to belong to the group of the strongest poisons among the known chemical compounds so far. Nevertheless, in spite of very high toxicity of certain dioxins and furans with regard to some animal organisms, one may find it difficult to compare PCDD/Fs with the other strong toxins present in the environment. This is because their activity is not instantaneous in the concentrations one encounters every day. According to the toxicological data it is difficult to acknowledge that they exhibit the so-called acute toxicity $[1,2]$. The harmful activity of PCDD/Fs concerns the fact that they disturb the endocrine functions of an organism, resulting in the fertility disorders, the problems with pregnancy, or even infertility (the chemical structure of dioxins bears a strong resemblance to the steroid hormones, including sex hormones). This is connected with disorders in progesterone release, the hormone being indispensable to hold pregnancy and to the appropriate course of pregnancy $[3,4]$. In contrast, the results concerning the carcinogenic activity of dioxins were not confirmed $[5,6]$. De facto, one should not neglect the 
way dioxins and furans affect a human organism. Hence, all activities aimed at the restriction of the emission of dioxins to the atmosphere are fully justified.

\section{Dioxins Emission Sources}

Based on the known results of investigations carried out for over twenty years it is known today that dioxins (polychlorinated dibenzo-p-dioxins -PCDDs) and furans (polychlorinated dibenzo-furans -PCDFs) form as an undesirable side product in practically all combustion processes (including incineration processes of waste: municipal, industrial and medicinal waste or sewage sludge as well as during combustion of fossil fuels, particularly hard coal, brown coal and biomass). Furthermore, dioxins form during certain industrial production processes such as pesticide, paper and cellulose production and in iron and steel industry and in nonferrous metallurgy. Even in the 70s and $80 \mathrm{~s}$ waste incineration plants were the main source of PCDD/Fs emission in the vast majority of countries all over the world. At present, as a result of restriction of emission norms and due to the development of new incineration technologies and the application of efficient systems of flue gases treatment, the situation has changed. Consequently, contemporary waste incineration plants emit flue gases containing dioxins and furans in such a concentration that is usually present in the polluted city air. The fact that chloroorganic pesticides have been withdrawn from production and that paper whitening with chlorine has been stopped has contributed to a considerable decrease of dioxin and furan emission in those processes as well. Nowadays, a significant dioxin emission source is metallurgy industry both in Poland and in many European countries comprising ferrous and nonferrous industry as well as secondary scrap processing. However, to very serious problems one may account noncontrollable incineration of household waste in domestic furnaces and combustion of solid fuels of low quality, including hard and brown coal in small local boiler rooms being obsolete and exploited. The incineration conditions are there very bad considering thermodynamics and chemistry of incineration. At the moment these are the main sources of dioxin emission to the atmosphere in the vast majority of European countries and in Poland [7].

Presently, the basic and the most important dioxin emission source in the vast majority of industrialized countries of the European Union is municipal heating sector being usually equipped with obsolete energy boilers of small in which there takes place the combustion of fuels of low quality under bad conditions (high concentrations of carbon monoxide) and equipped with individual heating systems frequently incinerating wood waste [8].

As mentioned above, humanity has been accompanied with dioxin emission since time immemorial. Investigations carried out in recent years indicate that it is possible to identify dioxins in high concentrations in many environmental samples. This also concerns samples originating from the period before industrial boom in the 19th century [9-11].
The first information about dioxins originating from the combustion process appeared in 1977-1978. Olie [12] found dioxins in flue gases from Dutch waste incineration plants and, subsequently, Buser [13] also confirmed the presence of dioxins in fly ashes from Swiss waste incineration plants.

Then the theory appeared that polychlorinated dibenzop-dioxins and polychlorinated dibenzo-furans originate from combustion processes- and it was termed trace chemistry of fire from the title of the article being published in the respected and prestigious journal "Science" in 1980 [14]. According to the theory, the basic sources of dioxin emission to the atmosphere and, particularly, to the environment, there may be as follows: waste incineration plants, power plants heated with mineral fuels, car engines (petrol and diesel), fire places, barbecues and cigarettes. To summarize, in 1992, the first decade of intensive investigations concerning dioxins, Rappe [15] concluded that environmental pollution due to dioxins may result from emission from the following sources.

(i) Chemical Reactions. This is the result of side reactions occurring in the processes of chemical synthesis, for example, the production of chlorinated pesticides, chloro-phenoxy-herbicides, chlorophenols, and PCB. Another relevant source is also the production and chemical utilization of chlorine, particularly electrolysis combined with chlorine production, cellulose pulp whitening with chlorine, and so forth.

(ii) Thermal Processes. This concerns first and foremost municipal, medicinal,and chemical waste incineration as well as iron, steel, magnesium, and nickel production. Moreover, the sources of dioxin emission to the environment are flue gases.

(iii) Photochemical Reactions. One may account here photochemical dechlorination of higher chlorinated dioxins-generation of more toxic congenerslower chlorinated, photochemical o-phenoxy-phenol cyclization or photochemical chlorophenol dimerization.

(iv) Enzymatic Reactions. This is the process of PCDD/F formation from chloro-phenols under an influence of peroxidases which may occur under the natural conditions, for example, in bioslurry, sewage sludge or bottoms of rivers, and lakes.

In 2000 Baker [16] asked a fundamental question whether incineration is the main source of dioxin emission to the environment. He formulated the thesis that dioxin emission is a fundamental feature of economical development and the quantity of dioxin emission in a given country depends mainly on GDP and it is proportional to $\mathrm{CO}_{2}$ emission as well.

Today, analyzing the available plentiful subject literature it may be recognized that the main sources of dioxin emission to the environment are first and foremost thermal processes, both incineration and others, for instance, metallurgic, chemical, photochemical, and biological ones [17]: 
(i) waste incineration: municipal, medicinal and hazardous waste, and incineration of sewage sludge,

(ii) cement production and waste coincineration in cement plants,

(iii) energetic combustion of fuels and waste coincineration in power plants,

(iv) wood incineration in industrial and household devices,

(v) fuel combustion in small household furnaces,

(vi) illegal waste incineration,

(vii) fuel combustion in car engines,

(viii) crematories,

(ix) paper industry,

(x) metallurgy,

(xi) chemical and textile industry,

(xii) fires, including forest fires,

(xiii) volcano eruption,

(xiv) cigarette smoking,

(xv) biological and photochemical processes.

\section{Dioxins Formation Mechanisms}

Polychlorinated dibenzo-p-dioxins and polychlorinated dibenzo-furans form practically in each combustion process $[14,18]$ of solid and liquid fuels (more seldom gaseous fuels) if chlorine, oxygen and organic matter appear in the zone of the appropriate temperatures. The thesis is valid not only for combustion processes but also for the majority of thermal processes taking place at the temperatures of $200-700^{\circ} \mathrm{C}$. The general course of the reaction is as follows:

$$
\mathrm{R}-\mathrm{Cl}+\mathrm{O}_{2} \underset{\text { combustion(oxidation) } t=200 \div 700^{\circ} \mathrm{C}}{\longrightarrow} \frac{\mathrm{PCDD}}{\mathrm{FS}}
$$

In case of waste incineration plant a given range of temperatures indicates unequivocally that dioxin synthesis occurs beyond the incineration zone. The investigations carried out by Hunsinger [19] proved among others that temperature above $900^{\circ} \mathrm{C}$ and deficiency of oxygen cause a complete dioxin decomposition. This means that dioxin synthesis may occur only after final air supply to the process and at the temperatures below $900^{\circ} \mathrm{C}$.

Based on numerous results of investigations of dioxin formation process three possible ways of dioxin formation have been proposed:

(i) the reaction in gaseous phase at the temperature of $500-700^{\circ} \mathrm{C}[20]$,

(ii) dioxin formation from molecular and organic carbon or inorganic chlorine in the presence of volatile ash at the temperature of $250-350^{\circ} \mathrm{C}$ called de novo synthesis [21], (iii) synthesis from various types of organic precursors such as chlorophenols, polychlorinated diphenylethers, polychlorinated biphenyls, and other products of incomplete combustion which may react with themselves both in gaseous phase and on the surface of metals being present in the composition of volatile ash [22].

In the light of results of the investigations it follows that the most important mechanism resulting in the highest production of dioxins is the third mechanism, then the second one and the lowest production of dioxins may be observed as for the first mechanism [23].

In the combustion process, at the temperatures higher than $900^{\circ} \mathrm{C}$ carbohydrate radicals and flammable gases are released from incinerated waste and other solid and liquid fuels. Subsequently, they participate in many complex synthesis reactions (halogenations, oxy-halogenation, oxidation, recombination and disproportionation) [24-27] resulting in the production of the so-called products of incomplete combustion. To the category of incomplete combustion products one may account phenols and chlorophenols, chlorobenzens, alkylobenzens, simple aliphatic carbohydrates, aldehydes and ketones, alcohols and simple carboxyl acids [28-31].

Chlorophenols, chlorobenzens or polychlorinated biphenyls and polychlorinated naphtalens constitute a group of dioxin precursors which at the temperature of $500-700^{\circ} \mathrm{C}$ may combine giving polychlorinated dibenzo-p-dioxins and polychlorinated dibenzo-furans. Those precursors may react with themselves both at the temperature $500-700^{\circ} \mathrm{C}$ in gaseous phase [20] and on the surface of volatile ash at the temperature of $200-500^{\circ} \mathrm{C}[32,33]$.

De novo synthesis occurs at the temperature of 200$500^{\circ} \mathrm{C}$ from molecules of carbon contained in volatile ash reacting with oxygen and chlorine on the surface of a catalyst $[21,34,35]$. The carbon source in de novo synthesis is the most frequently the so-called elementary carbon contained in the molecules of volatile ash as the remaining part after the processes of thermal decomposition and oxidation in the combustion process. In practice it is not possible to attain complete burn-up of carbon contained in fuel and small amounts of carbon which is only partially burnt up occur in waste gases in the form of soot. The key for molecules chlorination in de novo synthesis is Deacon's reaction [36] of catalytic oxidation of hydrogen chloride (formed during combustion) to molecular chlorine, being capable of carrying out the reaction of chlorination. The reaction is catalyzed by copper compounds $(\mathrm{Cu}, \mathrm{CuCl}$, $\mathrm{CuCl}_{2}, \mathrm{CuO}, \mathrm{Cu}_{2} \mathrm{O} \mathrm{i} \mathrm{CuSO}_{4}$ ) [37]. In reality, numerous metals are located on the surface of volatile ash having a various influence on the process of dioxin synthesis - certain metals catalyze the process of de novo synthesis or catalyze the process of chlorination of low chlorinated dioxins formed earlier (in the synthesis in a gaseous phase). To exemplify, one may account here copper, zinc, molibdenium, manganese, iron, aluminium, magnesium and other metals catalyze decomposition of the remaining dioxins or relatively their dechlorination, for instance, chromium, vanadium, tungsten, cobalt and nickel [38]. De novo synthesis is a 
slow, frequently very slow, reaction and the reaction of dioxin formation for instance from chlorophenols is about $10^{2}-10^{5}$ times faster [39]. Therefore, de novo synthesis occurs in combustion installation (not only but also in other thermal processes, e.g., metallurgic ones) beyond the combustion zone at the temperature of $200-400^{\circ} \mathrm{C}$, on molecules of deposited volatile ash. According to Goldfarb, the majority of dioxins generated in waste incineration plants is formed in accordance with this mechanism [40].

\section{Methods of Dioxins Emission Reduction}

The methods limiting the emission of dioxins from technological processes may be divided into two groups: the primary and secondary methods. The primary methods may be defined as the interference into a technological process and creation of such conditions of its course that the amount of dioxins is possibly the smallest [41]. Secondary methods are the so-called "end-of-pipe technologies" allowing to decrease their emission to the atmosphere.

Among the primary methods, the problem of crucial importance is to avoid the presence of chlorine in thermal processes. The processes of dioxins formation are nonequilibrium processes and even the trace amount of chlorine and organic material in the elevated temperature zone (200$700^{\circ} \mathrm{C}$ ) must result in the production of dioxins. Unfortunately, the presence of chlorine is frequently unavoidable.

The next factor one shall attach importance to is the temperature-dioxins are not so persistent chemical compounds as they are widely considered to be and they are decomposed at the temperature of $700^{\circ} \mathrm{C}$ [42]. Unfortunately, the vast majority of dioxins in thermal processes are produced as a result of the so-called "de novo" synthesis and the optimal range of the temperatures used in "de novo" synthesis is $300-350^{\circ} \mathrm{C}$. Analogously, one may observe the production of dioxins during the process of gas cooling from the temperature of $700^{\circ} \mathrm{C}$ to $200^{\circ} \mathrm{C}$. The amount of dioxins produced as a consequence of "de novo" synthesis is inversely proportional to the rate of gas cooling (taking away the heat); thus, it is essential that one aims at the building of very efficient systems of heat recovery (heat exchangers) and the eventual cooling of gases by quenching [43]. Furthermore, the presence of carbon monoxide and soot as well as dust (particulates) containing metals (for example, copper, iron, nickel, aluminum or zinc) favors "de novo" synthesis [42]. That is why, to the primary methods of the emission limitation one may account flue gases afterburning (so as to minimize the presence of carbon monoxide and soot) as well as hot gas scrubbing or such adjustment of the flow rate by the systems of heat recovery that the gas which is contained in those systems is not deposited on them. The formation of zones in the system of heat recovery, on which one may observe the process of dust and soot deposition, brings about an increase in the amount of dioxins as a result of "de novo" synthesis" [17]. What allows to decrease the emission of dioxins formed as a result of de-novo synthesis is to apply a quick and effective cooling of flue gases from the temperature of about $400^{\circ} \mathrm{C}$ to the temperature below $200^{\circ} \mathrm{C}$. The flue gases cooling rate has an important meaning for the quantity of dioxins formed. From the data contained in the subject literature [44] one may infer that in case of cooling of flue gases in a typical heat exchanger with the normal rate of the order $100-200^{\circ} \mathrm{C} / \mathrm{s}$ dioxin concentration at outlet is equal to about $5 \mathrm{ng} \mathrm{TEQ} / \mathrm{m}^{3}$ whereas to achieve dioxin concentration equal to about $1 \mathrm{ng}$ $\mathrm{TEQ} / \mathrm{m}^{3}$ it would be necessary to attain the cooling rate of the order $500-1000^{\circ} \mathrm{C} / \mathrm{s}$.

In the processes of combustion the issue of utmost importance is the appropriate control of combustion so that it is so similar to the process of complete combustion as it is possible [43]. The research of combustion and formation of organic micro-pollutants (e.g., the products of incomplete combustion) in this process led to the conclusion [45] that one of the most important parameters determining their emission, including dioxins, is the concentration of carbon monoxide in flue gases, in other words the quality of combustion. Those observations were confirmed by Seeker [46]. According to his research the concentration of carbon monoxide, in other words the conditions of combustion, considerably influences the amount and emission of dioxins generated in this process.

To the primary methods of the restriction of dioxins emission one may account the presence of sulphur dioxide in flue gases due to its inhibition of the dioxins synthesis. During the extensive research into waste combustion processes, it was concluded that the presence of sulphur dioxide in the combustion zone decreases to a large extent the amount of dioxins. Indeed, in the gas phase one may observe [47, 48] the reaction between chlorine and sulphur dioxide:

$$
\mathrm{SO}_{2}+\mathrm{Cl}+\mathrm{H}_{2} \mathrm{O} \longrightarrow \mathrm{SO}_{3}+2 \mathrm{HCl}
$$

The reaction has become an argument in the debates concerning the possibility of waste cocombustion in power stations and thermal-electric power stations. The results of the research carried out by US EPA and the confirmation of dioxins emission from combustion processes have made it possible to perceive the problem in a different way. It is essential to remember that at the elevated temperature one may notice the competitive Deacon's reaction-the catalytic decomposition of $\mathrm{HCl}$ [49]:

$$
4 \mathrm{HCl}+\mathrm{O}_{2} \underset{\text { catalyst }(\mathrm{Cu}, \mathrm{Fe}, \mathrm{Al})}{\longrightarrow} 2 \mathrm{Cl}_{2}+2 \mathrm{H}_{2} \mathrm{O}
$$

Hence, it is obvious that no chance of the complete elimination of dioxins in the combustion process exists. Further research concerning an impact of sulphur dioxide on the emission of dioxins indicates that the inhibitive influence of sulphur dioxide is not so high and strongly dependent on its excess. On the other hand, Deacon's reaction possesses its own optimum being dependent on the temperature and concentration of $\mathrm{HCl}$.

It must be underlined that good results in the scope of the limitation of dioxins production are obtained using 
inhibitors. To the most frequently encountered inhibitors there belong nitrogen and sulphur compounds which bring about the blocking of the metallic active centers in the particles of volatile dust, on the surface of which one may notice "de novo" synthesis [50-54].

To summarize, one shall state that the aforementioned primary methods of the restriction of dioxins emission have a chance to substantially decrease the amount of dioxins but it is not possible to completely eliminate their production. Moreover, in practice, one may observe that it is not possible to reduce the concentration of dioxins in flue gases below the required level $0.1 \mathrm{ng} \mathrm{TEQ} / \mathrm{m}^{3}$ using only the primary methods.

As regards the secondary methods of the reduction of dioxins emission, the methods of utmost importance are the following:

(i) adsorption on the activated carbon (on solid medium or the stream method)

(ii) catalytic decomposition of dioxins in the vanadium catalyst,

(iii) the filtrating-catalytic method "REMEDIA",

(iv) the absorbing-adsorbing method "ADIOX",

(v) the radiation method (using an electron beam),

(vi) the corona discharge method,

(vii) adsorption on carbon nanotubes,

(viii) nanocatalysis.

Dioxins, analogously to the majority of chemical substances are well adsorbed on active carbon [55]. Two variants of the adsorption process are known: the adsorption on the solid bed [56-58] and the so-called stream adsorption. In the first case great adsorbers filled with active carbon are the most frequently used. Active carbon should be replaced at the regular time intervals. The variations of those devices are the adsorbers with a moving bed of active carbon, which operate in the flowing manner [59-61]. The carbon used is the most frequently directed to combustion taking place in waste incineration plant. Another variation may be the application of adsorbers with fluidized bed [62] 1 or with monolithic static, packed bed [63]. The stream absorption is connected with the introduction of certain amounts of powdered active carbon (sometimes in the mixture with powdery calcium oxide known as Sorbalit, Sorbacal, Spongiacal, etc.) to the stream of flowing gases and, then, gas scrubbing on a fabric filter [64]. The method of adsorption on the solid or moving bed of active carbon has found its application to municipal waste incineration plants—such a solution was used in the modern (accepted to the public use in 1998) waste incineration plant in Cologne, in the hazardous waste and sewage sludge incineration plant EBS Simmering in Vienna and in the only one Polish waste incineration plant in Warsaw. In medical waste incineration plants there is a widely used method of stream adsorption combined with dry desulphurization using Sorbalit as a sorbent. It must be added that the stream adsorption method of dioxins elimination has been used with success in one of the Belgian steel plants recently. The efficacy of dioxins elimination usually attains the value of $95 \%$. The adsorption methods also present some disadvantages such as the problem of the used adsorbent management which comprises considerable amounts of dioxins as well as heavy metals $(\mathrm{Hg}$ in particular). The method with the application of active carbon (most of all, the adsorption on the solid bed) has one important flaw, namely the possibility of spontaneous carbon ignition at the elevated temperature (above $200^{\circ} \mathrm{C}$ ) and fire of the installation. Therefore, the application of the method of the reduction of dioxins emission is gradually diminished.

It must be highlighted that the catalytic method is deprived of this disadvantage. During the exploitation of the catalytic systems of NOx removing from flue gases it was noticed that dioxins in waste gas are subject to the efficacious decomposition. The research done by Hagenmeier [65] indicates that the vanadium-tungsten catalyst on the titanium oxide carrier effectively decomposes $\mathrm{PCDD} / \mathrm{Fs}$ with the release of carbon dioxide, water and $\mathrm{HCl}$. Such a catalyst is widely used in the catalytic reduction of nitrogen oxide (with the addition of ammonia) in the process of selective catalytic reduction known as SCR (Selective Catalytic Reduction). Further research [66-76] indicated that it is feasible to effectively reduce the emission of both nitrogen oxides and $\mathrm{PCDD} / \mathrm{Fs}$ on the appropriately prepared catalyst $\mathrm{V}_{2} \mathrm{O}_{5}-$ $\mathrm{WO}_{3} / \mathrm{TiO}_{2}$ in the presence of ammonia. Today it is known that on the tungsten or platinum catalyst one may observe dechlorination and oxidation of dioxins (the partition of those processes-dechlorination and oxidation-is dependent on the composition of the catalyst) [77].

The products of those reactions are carbon dioxide, water and $\mathrm{HCl}$. The temperature of the process is in the range of $250-300^{\circ} \mathrm{C}$. The efficacy of dioxins elimination using the catalytic methods is 95-99\% [78]. The numerous industrial applications confirm the high efficacy of the method [79]. It must be added that a lot of research was conducted using the other catalysts such as the platinum or perovskite catalysts. Yet those trials with platinum catalyst were completed with no success due to the secondary synthesis of dioxins on the catalyst [80-83]. To the disadvantages of the catalytic method one may account its high price, almost double as high when compared to the systems with the sorbent injection and a fabric filter and slightly higher than the systems with a moving bed of active carbon.

It is quite recently that a new method of dioxins elimination from waste gases has appeared. The method has been developed in the GORE Associates Company under the name "REMEDIA" [84-87] and it comprises such methods as the adsorption, dedusting and catalytic decomposition. The main part constitutes the membranes produced from teflon and glass fibers, specially modified with the layer of vanadium compounds. The membranes operate at the temperatures $180-250^{\circ} \mathrm{C}$. On the layer of dust separated on the filtrating membranes the preliminary adsorption of dioxins occurs (those which are in the solid form). On the other hand, those dioxins which were not absorbed are subject to dechlorination and oxidation using vanadium salts deposited on the membrane. The efficacy of dioxins 
elimination is equal to $95 \%$. According to the scientists who developed the method it is slightly cheaper that the method with the injection of the sorbent and fabric filter and $60 \%$ cheaper than the catalytic systems. The experiments in using the filtrating - catalytic method in the IVRO municipal waste incineration plant in Roeselare (the capacity of 2 lines $47000 \mathrm{Mg} / \mathrm{a}$ ) in Belgium are positive though [88, 89]. As a result of the observations lasting 42 months it was confirmed that $99.95 \%$ of the restriction of dioxins emission and the systematic maintenance of the dioxins concentration in waste gases is in the range of $0.008-0.037 \mathrm{ng} \mathrm{TEQ} / \mathrm{m}^{3}$. It must be added that recently a similar installation has been used in the municipal waste incineration plant in Liberec in the Czech Republic [90].

The absorbing-adsorbing method (ADIOX) has been recently developed by the Swedish company Götaverken Miljö. The method applies the so-called "memory effect" [91] being observed in waste incineration plants. The effect is based on the absorption of dioxins in the elements of the flue gases cleaning systems made of plastics (i.e., polypropylene) and their subsequent desorption from the packing elements to the stream of flue gases in the case of the relevant decrease of their concentration in the flue gas stream as a result of, for instance, the application of the primary methods of the reduction of emission.

The solution of ADIOX encompasses the introduction of activated carbon into polypropylene applied to the process of the elements of flue gases wet purification (mainly packing elements). The molecules of dioxins, which have been absorbed in polypropylene, are additionally adsorbed on the surface of activated carbon and, efficaciously, eliminated from the flue gas stream in a persistent manner. The used elements, saturated with dioxins, are, after the replacement, burnt in waste incineration plant. Due to the fact that the process of dioxins production is a nonequilibrium process it does not influence an increase in PCDD/Fc emission from the emitter of incineration plant. The method was applied in several municipal and hazardous waste incineration plants (i.e., Kloding, Thisted, Fasan, Glostrup in Denmark, Umeå, Holstebro and Malmö in Sweden, Tredi Salaise in France and Trondheim in Norway) with a good result [92-98].

The search for the new methods of the reduction of dioxins emission is being continued. The promising effects provides the application of a radiation method (with a beam of electrons) [99-105] used till now to the simultaneous elimination of sulphur dioxide and nitrogen oxides in power plants. Furthermore, it is reported that the application of corona discharge permits one to reduce the emission of dioxins [106, 107]. There has also appeared the proposition of using the XXI-century technique-nanotechnology to remove dioxins. One of the variations is using the unique adsorbing abilities of carbon nanotubes [108-112], another is using the nanoparticles of transition metals (e.g., titanium, vanadium) introduced to flue gases the presence of which causes the catalytic decomposition of dioxins [113-116]. Nonetheless, this research is being carried out on a laboratory scale, analogously to the first examinations using ionic liquids in the selective absorption of dioxins and furans [117].

\section{Recommendations}

The problem of dioxin emission is identified the most frequently with waste incineration and it has been solved in the most satisfactory way in waste incineration plants. A considerable number of municipal waste incineration plants and big hazardous waste incineration plants have been equipped with the systems of catalytic reduction of nitrogen oxides being as well reactors of PCDD/Fs catalytic decomposition. Certain installations have been equipped with huge adsorbers with moving activated coke bed. More and more installations apply today a filtration-catalytic method (REMEDIA) or an adsorbing-absorbing method (ADIOX). In case of small medicinal waste or other hazardous waste incineration installations a basic method is the use of calcium reagent (lime) for acidic gas removal (e.g., Sorbalit, Sorbacal, Spongiacal, etc.) provided with ca. 5-10\% addition of powder activated carbon. In combination with fabric filter the efficiency of dioxin removal using this method is very high. Part of those small installations are equipped with a catalytic reactor SCR in which PCDD/Fs decomposition also takes place. However, waste incineration plants are not the only sources of dioxin emission from industry. The Stockholm Convention imposes the reduction of their emission from all sources. Seemingly, the problem of dioxin emission from large combustion plants i.e. electric power stations and thermal-electric power stations, constitutes no problem. Numerous research results published in literature [118-121] indicate that for hard coal combustion PCDD/Fs concentrations do not usually exceed $0.01 \mathrm{ng} \mathrm{TEQ} / \mathrm{m}^{3}$ and, hence, they are at least 10-times lower than the values allowed for waste incineration. A similar situation takes place in case of lignite [122] or oil combustion [123]. This is the result of sulfur content in fuel and fixation of chlorine capable of taking part in chlorination reaction during de novo synthesis. The most recent investigations performed by Konieczyński and Grochowalski [124] proved that there is a visible dependence between dioxin concentration in flue gases and the size of installation for coal combustion-in case of small boilers dioxin concentrations in flue gases applied in households may slightly exceed $0.1 \mathrm{ng} \mathrm{TEQ} / \mathrm{m}^{3}$. Great possibilities of reduction of dioxin emission from power plants are connected with the application of technology of simultaneous $\mathrm{SO}_{2}$ and $\mathrm{NO}_{x}$ removal utilizing electron beam technology [104, 105]. Apart from reduction of those two pollutants there also occurs decomposition and oxidation of PCDD/Fs with good efficiency.

A relevant source of dioxin emission to the environment is metallurgy sector. There are a lot of data proving that dioxin concentrations in waste gases may reach the level of 50-1200 ng TEQ/m ${ }^{3}$ [125-129]. In this sector there are no regulations reducing dioxin concentrations in waste gases at present (with the exception of Belgium and Canada). Nevertheless, in many countries installations reducing dioxin emission using a filtration-catalytic method (REMEDIA) $[84,85]$ have appeared in the recent years. The second method used in metallurgy sector is the application of inhibitors based on chemical compounds containing nitrogen and sulfur in a molecule, for example, urea, ammonium 
sulfate, and so forth, [50-54]. Seemingly, the method has great perspectives in metallurgy sector due to a relatively low cost.

In conclusion, amongst the secondary methods of dioxin emission reduction one may recommend the catalytic method as the most important and the most efficacious one allowing to decrease simultaneously and considerably the emission of $\mathrm{PCDD} / \mathrm{Fs}$ and reduce the emission of nitrogen oxides (SCR). Very good results are also attained by the application of filtration-catalytic method. Numerous installations give a chance to disseminate the technology in industry as well. The obstacle may be a high price of filtrating sacks applied in this method. However, it seems to be that the utilization of adsorption technologies using active carbon has only slight chances to be implemented. The utilization of radiation method (with an electron beam) may also be promising as it is an effective method of reduction of sulphur dioxide and nitrogen oxide emission being implemented on a commercial scale of production. The application of adsorption to carbon nanotubes seems to be very intriguing; however, the actual state of technique does not give a chance to implement the method on a large scale.

\section{Conclusions}

The problem of dioxin emission from combustion processes really exists. The intensity of this emission is the resultant of combustion conditions and the effectiveness of flue gases treatment system. However, it must be remembered that even the most novel and the greatest system of flue gases treatment is not able to dispose of all pollutants, particularly in case of unstable installation operation and changing parameters of gases subjected to treatment. The key here is continuous, stable installation work, combustion of low emissivity and the appropriate conservation. These are the conditions to be obeyed so that the properly designed installations with an efficient system of flue gases treatment have the emission in accordance with the regulations [130]. All oscillations of work parameters, particularly carbon dioxide concentration oscillations will always result in the increased dioxin emission.

However, seemingly, after 30 years of investigations concerning dioxin formation and methods of reduction of their emission we may say that we have been acquainted with the process so thoroughly to prevent effectively dioxin formation and to reduce their emission to the level which is not hazardous to the environment and human health.

\section{References}

[1] A. Poland and J. C. Knutson, "2,3,7,8-tetrachlorodibenzop-dioxin and related halogenated aromatic hydrocarbons: examination of the mechanism of toxicity," Annual Review of Pharmacology and Toxicology, vol. 22, pp. 517-554, 1982.

[2] D. W. Boening, "Toxicity of 2,3,7,8-tetrachlorodibenzo-pdioxin to several ecological receptor groups: a short review," Ecotoxicology and Environmental Safety, vol. 39, no. 3, pp. 155-163, 1998.
[3] M. Kogevinas, "Human health effects of dioxins: cancer, reproductive and endocrine system effects," Human Reproduction Update, vol. 7, no. 3, pp. 331-339, 2001.

[4] A. J. J. Mendes, "The endocrine disrupters: a major medical challenge," Food and Chemical Toxicology, vol. 40, no. 6, pp. 781-788, 2002.

[5] P. Cole, D. Trichopoulos, H. Pastides, T. Starr, and J. S. Mandel, "Dioxin and cancer: a critical review," Regulatory Toxicology and Pharmacology, vol. 38, no. 3, pp. 378-388, 2003.

[6] P. Boffetta, "Human cancer from environmental pollutants: the epidemiological evidence," MMutation Research/Genetic Toxicology and Environmental Mutagenesis, vol. 608, no. 2, pp. 157-162, 2006.

[7] “The European Dioxin Emission Inventory. Stage II," European Commission DG ENV, Bruxelles, Belgium, 2000.

[8] G. Thanner and W. Moche, Emission von Dioxinen, PCBs und PAHs aus Kleinfeuerungen, vol. 153 of Monographien, Umweltbundesamt, Wien, Austria, 2002.

[9] W. V. Ligon Jr., S. B. Dorn, R. J. May, and M. J. Allison, "Chlorodibenzofuran and chlorodibenzo-p-dioxin levels in Chilean mummies dated to about 2800 years before the present," Environmental Science and Technology, vol. 23, no. 10, pp. 1286-1290, 1989.

[10] R. E. Alcock and K. C. Jones, "Dioxins in the environment: a review of trend data," Environmental Science and Technology, vol. 30, no. 11, pp. 3133-3143, 1996.

[11] R. E. Alcock, M. S. Mclachlan, A. E. Johnston, and K. C. Jones, "Evidence for the presence of PCDD/Fs in the environment prior to 1900 and further studies on their temporal trends," Environmental Science and Technology, vol. 32, no. 11, pp. 1580-1587, 1998.

[12] K. Olie, P. L. Vermeulen, and O. Hutzinger, "Chlorodibenzop-dioxins and chlorodibenzofurans are trace components of fly ash and flue gas of some municipal incinerators in the Netherlands," Chemosphere, vol. 6, no. 8, pp. 455-459, 1977.

[13] H. R. Buser, H.-P. Bosshardt, and C. Rappe, "Identification of polychlorinated dibenzo-p-dioxin isomers found in fly ash," Chemosphere, vol. 7, no. 2, pp. 165-172, 1978.

[14] R. R. Bumb, W. B. Crummett, and S. S. Cutie, "Trace chemistries of fire: a source of chlorinated dioxins," Science, vol. 210, no. 4468, pp. 385-390, 1980.

[15] C. Rappe, "Sources of PCDDs and PCDFs. Introduction. Reactions, levels, patterns, profiles and trends," Chemosphere, vol. 25, no. 1-2, pp. 41-44, 1992.

[16] J. I. Baker and R. A. Hites, "Is combustion the major source of polychlorinated dibenzo-p-dioxins and dibenzofurans to the environment? A mass balance investigation," Environmental Science and Technology, vol. 34, no. 14, pp. 2879-2886, 2000.

[17] G. Wielgosiński, Dioxins Emission from Thermal Processes, PAN, Łódź, Poland, 2009.

[18] W. B. Crummett and D. I. Townsend, "The trace chemistries of fire hypothesis: review and update," Chemosphere, vol. 13, no. 7, pp. 777-788, 1984.

[19] H. Hunsinger, K. Jay, and J. Vehlow, "Formation and destruction of $\mathrm{PCDD} / \mathrm{F}$ inside a grate furnace," The Chemosphere, vol. 46, no. 9-10, pp. 1263-1272, 2002.

[20] K. Ballschmiter, W. Zoller, H. Buchert, and T. H. Clas, "Correlation between substitution pattern and reaction pathway in the formation of polychlorodibenzofurans," Fresenius' Zeitschrift für Analytische Chemie, vol. 322, no. 6, pp. 587594, 1985. 
[21] H. Vogg and L. Stieglitz, "Thermal behavior of PCDD/PCDF in fly ash from municipal incinerators," Chemosphere, vol. 15, no. 9-12, pp. 1373-1378, 1986.

[22] F. W. Karasek and L. C. Dickson, "Model studies of polychlorinated dibenzo-p-dioxin formation during municipal refuse incineration," Science, vol. 237, no. 4816, pp. 754-756, 1987.

[23] H. Huang and A. Buekens, "On the mechanisms of dioxin formation in combustion processes," Chemosphere, vol. 31, no. 9, pp. 4099-4117, 1995.

[24] K. Ballschmiter and M. Swerev, "Reaction pathways for the formation of polychlorodibenzodioxins (PCDD) and -furans (PCDF) in combustion processes I," Fresenius' Zeitschrift für Analytische Chemie, vol. 328, no. 1-2, pp. 125-127, 1987.

[25] K. Ballschmiter, I. Braunmiller, R. Niemczyk, and M. Swerev, "Reaction pathways for the formation of polychlorodibenzodioxins (PCDD) and dibenzofurans (PCDF) in combustion processes: II. Chlorobenzenes and chlorophenols as precursors in the formation of poly-chloro-dibenzodioxins and dibenzofurans in flame chemistry," Chemosphere, vol. 17, no. 5, pp. 995-1005, 1988.

[26] W. A. Rubey, B. Dellinger, D. L. Hall, and S. L. Mazer, "High-temperature gas-phase formation and destruction of polychlorinated dibenzofurans," Chemosphere, vol. 14, no. 10, pp. 1483-1494, 1985.

[27] C. M. Young and K. J. Voorhees, "PIC formation mechanisms in the thermal decomposition of 1,2-dichlorobenzene," Chemosphere, vol. 23, no. 8-10, pp. 1265-1277, 1991.

[28] G. H. Eduljee, "Organic micropollutant emissions from waste incineration," in Waste Incineration and the Environment, R. E. Hester and R. M. Harrison, Eds., Royal Society of Chemistry, Cambridge, UK, 1994.

[29] K. Jay and L. Stieglitz, "Identification and quantification of volatile organic components in emissions of waste incineration plants," Chemosphere, vol. 30, no. 7, pp. 1249-1260, 1995.

[30] A. Trenholm, "Identification of PICs in hazardous waste combustion emissions," Waste Management, vol. 18, no. 6-8, pp. 485-492, 1998.

[31] J. Wienecke, H. Kruse, U. Huckfeldt, W. Eickhoff, and O. Wassermann, "Organic compounds in the flue gas of a hazardous waste incinerator," Chemosphere, vol. 30, no. 5, pp. 907-913, 1995.

[32] E. R. Altwicker, R. K. N. V. Konduri, C. Lin, and M. S. Milligan, "Formation of precursors to chlorinated dioxin/furans under heterogeneous conditions," Combustion Science and Technology, vol. 88, no. 5-6, pp. 349-368, 1993.

[33] L. C. Dickson, D. Lenoir, and O. Hutzinger, "Surfacecatalyzed formation of chlorinated dibenzodioxins and dibenzofurans during incineration," Chemosphere, vol. 19, no. 1-6, pp. 277-282, 1989.

[34] L. Stieglitz and H. Vogg, "On formation conditions of PCDD/PCDF in fly ash from municipal waste incinerators," Chemosphere, vol. 16, no. 8-9, pp. 1917-1922, 1987.

[35] L. Stieglitz, G. Zwick, J. Beck, W. Roth, and H. Vogg, "On the de-novo synthesis of PCDD/PCDF on fly ash of municipal waste incinerators," Chemosphere, vol. 18, no. 1-6, pp. 12191226, 1989.

[36] R. D. Griffin, "A new theory of dioxin formation in municipal sold waste combustion," Chemosphere, vol. 15, no. 9-12, pp. 1987-1990, 1986.

[37] B. K. Gullett, K. R. Bruce, L. O. Beach, and A. M. Drago, "Mechanistic steps in the production of PCDD and PCDF during waste combustion," Chemosphere, vol. 25, no. 7-10, pp. 1387-1392, 1992.

[38] T. Öberg, B. Bergbäck, and M. Filipsson, "Catalytic effects by metal oxides on the formation and degradation of chlorinated aromatic compounds in fly ash," Chemosphere, vol. 71, no. 6, pp. 1135-1143, 2008.

[39] L. C. Dickson, D. Lenoir, and O. Hutzinger, "Quantitative comparison of de novo and precursor formation of polychlorinated dibenzo-p-dioxins under simulated municipal solid waste incinerator postcombustion conditions," Environmental Science and Technology, vol. 26, no. 9, pp. 1822-1828, 1992.

[40] T. D. Goldfarb, "Evidence for post-furnace formation of PCDDs and PCDFs-implications for control," Chemosphere, vol. 18, no. 1-6, pp. 1051-1055, 1989.

[41] G. Wielgosiński, "Emissions from waste incineration plants_-primary methods of emission reduction," Energetic Policy, vol. 6, pp. 131-140, 2003.

[42] B. Gullett and R. Seeker, "Chlorinated dioxin and furan control and monitoring," in Proceedings of the Interfaith Center on Corporate Responsibility (ICCR '97), Research Triangle Park, 1997.

[43] R. Ishikawa, A. Buekens, H. Huang, and K. Watanabe, "Influence of combustion conditions on dioxin in an industrialscale fluidized-bed incinerator: experimental study and statistical modelling," Chemosphere, vol. 35, no. 3, pp. 465-477, 1997.

[44] K. Watanabe and K. Tsukamoto, "Emission control of dioxin compounds in plastic waste incineration," Organohalogen Compounds, vol. 19, pp. 431-434, 1994.

[45] G. Schmoekel and A. Streit, Emissionen Organischer Stoffe Bei Der Holzfeuerung Wackersdorf, Bayerisches Landesamt ftir Umweltschutz, Augsburg College, Minneapolis, MN, USA, 1994.

[46] R. Seeker, "Current understanding of dioxin/furan formation and control," private communication.

[47] R. L. Lindbauer, F. Wurst, and T. Prey, "Combustion dioxin suppression in municipal solid waste incineration with sulphur additives," Chemosphere, vol. 25, no. 7-10, pp. 14091414, 1992.

[48] B. K. Gullett, K. R. Bruce, and L. O. Beach, "Effect of sulfur dioxide on the formation mechanism of polychlorinated dibenzodioxin and dibenzofuran in municipal waste combustors," Environmental Science Technology, vol. 26, no. 10, pp. 1938-1943, 1992.

[49] H. Huang and A. Buekens, "De novo synthesis of polychlorinated dibenzo-p-dioxins and dibenzofurans. Proposal of a mechanistic scheme," The Science of the Total Environment, vol. 193, no. 2, pp. 121-141, 1996.

[50] P. H. Ruokojärvi, I. A. Halonen, K. A. Tuppurainen, J. Tarhanen, and J. Ruuskanen, "Effect of gaseous inhibitors on PCDD/F formation," Environmental Science and Technology, vol. 32, no. 20, pp. 3099-3103, 1998.

[51] C. Xhrouet and E. de Pauw, "Prevention of dioxins de novo synthesis by ethanolamines," Environment Chemistry Letters, vol. 1, pp. 51-56, 2003.

[52] P. H. Ruokojärvi, A. H. Asikainen, K. A. Tuppurainen, and J. Ruuskanen, "Chemical inhibition of PCDD/F formation in incineration processes," Science of the Total Environment, vol. 325, no. 1-3, pp. 83-94, 2004.

[53] S. Kuzuhara, H. Sato, N. Tsubouchi, Y. Ohtsuka, and E. Kasai, "Effect of nitrogen-containing compounds on polychlorinated dibenzo-p-dioxin/dibenzofuran formation through de 
novo synthesis," Environmental Science and Technology, vol. 39, no. 3, pp. 795-799, 2005.

[54] M. E. Pandelova, D. Lenoir, A. Kettrup, and K.-W. Schramm, "Primary measures for reduction of $\mathrm{PCDD} / \mathrm{F}$ in cocombustion of lignite coal and waste: effect of various inhibitors," Environmental Science and Technology, vol. 39, no. 9, pp. 3345-3350, 2005.

[55] J. J. Cudahy and R. W. Helsel, "Removal of products of incomplete combustion with carbon," Waste Management, vol. 20, no. 5-6, pp. 339-345, 2000.

[56] H. J. Fell and M. Tuczek, "Removal of dioxins and furans from flue gases by non-flammable adsorbents in a fixed bed," Chemosphere, vol. 37, no. 9-12, pp. 2327-2334, 1998.

[57] J. Blumbach and L. P. Nethe, "PCDD/F/PCB reduction in flue gases and residual materials from waste incineration by use of carbonaceous adsorbents," Organohalogen Compounds, vol. 19, pp. 305-310, 1994.

[58] S. Okajima, T. Kojima, S. Ueoka, and H. Ozaki, "Fixed-bed adsorption of polychlorinated dibenzo-p-dioxins and dibenzofurans from flue gas a municipal solid waste incinerator," Organohalogen Compounds, vol. 54, pp. 193-196, 2001.

[59] R. Maierhofer and H. Grochowski, "Removal of dioxins and furans with activated carbon countercurrent flow process," Organohalogen Compounds, no. 19, pp. 361-364, 1994.

[60] K. Everaert, J. Baeyens, and C. Creemers, "Adsorption of dioxins and furans from flue gases in an entrained flow or fixed/moving bed reactor," Journal of Chemical Technology and Biotechnology, vol. 78, no. 2-3, pp. 213-219, 2003.

[61] K. Everaert and J. Baeyens, "Removal of PCDD/F from flue gases in fixed or moving bed adsorbers," Waste Management, vol. 24, no. 1, pp. 37-42, 2004.

[62] K. Mori, H. Matsui, N. Yamaguchi, and Y. Nakagawa, "Multicomponent behavior of fixed-bed adsorption of dioxins by activated carbon fiber," Chemosphere, vol. 61, no. 7, pp. 941946, 2005.

[63] M. Yates, J. Blanco, P. Avila, and M. P. Martin, "Honeycomb monoliths of activated carbons for effluent gas purification," Microporous and Mesoporous Materials, vol. 37, no. 1-2, pp. 201-208, 2000.

[64] M. Reinmark, D. van der Kleut, and B. van der Akker, "Norit powdered activated carbon in flue gas clean up," Organohalogen Compounds, vol. 27, pp. 177-182, 1996.

[65] H. Hagenmeier, "Katalytische oxidation halogenierter kohlenwasserstoffe unter besonderer berücksichtigung des dioxinproblems," VDI Berichte, vol. 730, pp. 239-254, 1989.

[66] M. Hiraoka, N. Takeda, S. Okajima, T. Kasakura, and Y. Imoto, "Catalytic destruction of PCDDs in flue gas," Chemosphere, vol. 19, no. 1-6, pp. 361-366, 1989.

[67] H. Hagenmaier and G. Mittelbach, "Versuche zum Katalytischen NOx und Dioxin Abbau im Abgas einer Hausmüllverbrennungsanlage," VGB-Kraftwerkstechnik, vol. 70, no. 6, pp. 491-493, 1990.

[68] H. von Fahlenkamp, G. Mittlebach, H. Hagenmeier, H. Brunner, and K.-H. Tichaczek, "Katalytische Oxidation. Eine Technik zur Verminderung der PCDD-/PCDF-Emission aus Müllverbrennungsanlagen auf kleiner $0,1 \mathrm{ng} \mathrm{TE} / \mathrm{m}^{3}$," VGB kraftwerkstechnik, vol. 71, no. 7, pp. 671-674, 1991.

[69] R. Boos, R. Budin, H. Hartl, M. Stock, and F. Wurst, "PCDDand PCDF- destruction by a SCR-unit in a municipal waste incinerator," Chemosphere, vol. 25, no. 3, pp. 375-382, 1992.

[70] Y. Ide, K. Kashiwabara, S. Okada, T. Mori, and M. Hara, "Catalytic decomposition of dioxin from MSW incinerator flue gas," Chemosphere, vol. 32, no. 1, pp. 189-198, 1996.
[71] P. Andersson, C. Rappe, O. Maaskant, J. F. Unsworth, and S. Marklund, "Low temperature catalytic destruction of $\mathrm{PCDD} / \mathrm{F}$ in flue gas from waste incineration," Organohalogen Compounds, vol. 36, pp. 109-248, 1998.

[72] W. Schüttenhelm, R. Wemhöner, H. U. Hartenstein, and K. Werner, "Reduction of PCDD/F emission from iron ore sintering plants-the first full-scale SCR installation," Organohalogen Compounds, vol. 40, pp. 453-456, 1999.

[73] R. Weber, T. Sakurai, and H. Hagenmaier, "Low temperature decomposition of PCDD/PCDF, chlorobenzenes and PAHs by $\mathrm{TIO}_{2}$-based $\mathrm{V}_{2} \mathrm{O}_{5}-\mathrm{WE}_{3}$ catalysts," Applied Catalysis $B$, vol. 20, no. 4, pp. 249-256, 1999.

[74] H. C. Choi, C. G. Park, H. J. Seung, and Oh T. Y., "Catalytic destruction of PCDDs/DFs by the SCR units," Organohalogen Compounds, vol. 45, pp. 387-391, 2000.

[75] C. C. Hyun, G. P. Cheon, J. S. Hee, and T. Y. Oh, "Catalytic destruction of PCDDs/DFs by SCR units," Organohalogen Compounds, vol. 45, pp. 387-390, 2000.

[76] M. Goemans, P. Clarysse, J. Joannès et al., "Catalytic NOx reduction with simultaneous dioxin and furan oxidation," Chemosphere, vol. 54, no. 9, pp. 1357-1365, 2004.

[77] F. Bertinchamps, Total oxidation of chlorinated VOCs on supported oxide catalysts, Ph.D. thesis, Universite Catholique de Louvain, Louvain, Belgium, 2005.

[78] G. Wielgosiński, A. Grochowalski, T. Machej, T. Pająk, and W. Ćwiąkalski, "Catalytic destruction of dioxins on $\mathrm{V}_{2} \mathrm{O}_{5}$ $\mathrm{WE}_{3} / \mathrm{AL}_{2} \mathrm{O}_{3}-\mathrm{TIO}_{2}$ catalyst effect of temperature and catalyst loading," Organohalogen Compounds, vol. 60, pp. 2242-2245, 2005.

[79] E. Finocchio, G. Busca, and M. Notaro, "A review of catalytic processes for the destruction of PCDD and PCDF from waste gases," Applied Catalysis B, vol. 62, no. 1-2, pp. 12-20, 2006.

[80] V. de Jong, M. K. Cieplik, and R. Louw, "Formation of dioxins in the catalytic combustion of chlorobenzene and a micropollutant-like mixture on $\mathrm{Pt} / \gamma-\mathrm{AL}_{2} \mathrm{O}_{3}$," Environmental Science and Technology, vol. 38, no. 19, pp. 5217-5223, 2004.

[81] R. W. van den Brink, R. Louw, and P. Mulder, "Formation of polychlorinated benzenes during the catalytic combustion of chlorobenzene using a $\mathrm{Pt} / \gamma-\mathrm{AL}_{2} \mathrm{O}_{3}$ catalyst," Applied Catalysis B, vol. 16, no. 3, pp. 219-226, 1998.

[82] J. R. Hart, "Verification of dioxin formation in a catalytic oxidizer," Chemosphere, vol. 72, no. 1, pp. 75-78, 2008.

[83] G. Wielgosiński, A. Grochowalski, T. Machej, and W. Ćwiąkalski, "Dioxin Formation over Pt/Pd catalyst," in Proceedings of the 29th International Symposium on Halogenated Persistent Ogranic Pollutants (DIOXIN '09), Beijing, China, August 2009.

[84] M. Plinke, K. Fritsky, C. P. Gantara, et al., "Catalytic dioxin/furan removal from flue gas streams," Organohalogen Compounds, vol. 45, pp. 452-455, 2000.

[85] R. Weber, M. Plinke, and Z. Xu, "Dioxin destruction efficiency of catalytic filters-evaluation in laboratory and comparison to field operation," Organohalogen Compounds, vol. 45, pp. 427-430, 2000.

[86] K. J. Fritsky, J. H. Kumm, and M. Wilken, "Combined $\mathrm{PCDD} / \mathrm{F}$ destruction and particulate control in a baghouse: experience with a catalytic filter system at a medical waste incineration plant," Journal of the Air and Waste Management Association, vol. 51, no. 12, pp. 1642-1649, 2001.

[87] G. Pranghofer, "Destruction of polychlorinated dibenzo-pdioxins and dibenzofurans in fabric filters: recent experiences with a catalytic filter system," in Proceedings of the 3rd International Symposium on Incineration and Flue Gas Treatment 
Technologies (INCINERATION '01), Brussels, Belgium, June 2001.

[88] J. L. Bonte, M. Plinke, R. Dandaraw, et al., "Catalytic filtration: dioxin/furan destruction in the baghouse. Experiences at the IVRO municipal waste incinerator in Roeselare," Organohalogen Compounds, vol. 40, pp. 459-464, 1999.

[89] J. L. Bonte, K. J. Fritsky, M. A. Plinke, and M. Wilken, "Catalytic destruction of PCDD/F in a fabric filter: experience at a municipal waste incinerator in Belgium," Waste Management, vol. 22, no. 4, pp. 421-426, 2002.

[90] M. Syc, V. Pekarek, E. Fioserova, M. Puncochar, J. Karban, and O. Kokes, "Catalytic filter application in the termizo municipal waste incineration plant in Liberec," Organohalogen Compounds, vol. 68, pp. 1232-1235, 2006.

[91] S. Kreisz, H. Hunsinger, and H. Vogg, "Technical plastics as PCDD/F absorbers," Chemosphere, vol. 34, no. 5-7, pp. 10451052, 1997.

[92] S. Kreisz, H. Hunsinger, and H. Seifert, "Polypropylene as regenerable absorber for PCDD/F emission control," Chemosphere, vol. 40, no. 9-11, pp. 1029-1031, 2000.

[93] S. Kreisz, H. Hunsinger, and H. Seifert, "Carbon doped propylene as PCDD/F adsorber," Organohalogen Compounds, vol. 56, pp. 369-372, 2002.

[94] S. Andersson, S. Kreisz, and H. Hunsinger, "PCDD/F removal from flue gases in wet scrubbers-a novel technique," Organohalogen Compounds, vol. 58, pp. 157-160, 2002.

[95] S. Andersson, S. Kreisz, and H. Hunsinger, "Innovative material technology removes dioxins from flue gases," Filtration and Separation, vol. 40, no. 10, pp. 22-25, 2003.

[96] S. Andersson, S. Kreisz, and H. Hunsinger, "PCDD/F removal from flue gases using Adiox," Organohalogen Compounds, vol. 63, pp. 244-247, 2003.

[97] S. Andersson, "PCDD/F removal from gases using a dry adiox absorber," Organohalogen Compounds, vol. 67, pp. 22262229, 2005.

[98] S. Andersson, S. Kreisz, and H. Hunsinger, "Dioxin removal: ADIOX for wet scrubbers and dry absorbers," Filtration and Separation, vol. 42, no. 12, pp. 22-25, 2005.

[99] H.-R. Paur, W. Baumann, H. Mätzing, and K. Jay, "Electron beam induced decomposition of chlorinated aromatic compounds in waste incinerator offgas," Radiation Physics and Chemistry, vol. 52, no. 1-6, pp. 355-359, 1998.

[100] G. Y. A. Gerasimov, "Simulation of the nehavior of dioxins under the conditions of electron-beam gas cleaning of sulfur and nitrogen oxides," High Energy Chemistry, vol. 37, no. 3, pp. 141-145, 2003.

[101] H. Nichipor, E. Dashouk, S. Yacko, A. G. Chmielewski, Z. Zimek, and Y. Sun, "Chlorinated hydrocarbons and PAH decomposition in dry and humid air by electron beam irradiation," Radiation Physics and Chemistry, vol. 65, no. 45, pp. 423-427, 2002.

[102] K. Hirota, T. Hakoda, M. Taguchi, M. Takigami, H. Kim, and T. Kojima, "Application of electron beam for the reduction of PCDD/F emission from municipal solid waste incinerators," Environmental Science and Technology, vol. 37, no. 14, pp. 3164-3170, 2003.

[103] A. G. Chmielewski, Y.-X. Sun, S. Bulka, and Z. Zimek, "Chlorinated aliphatic and aromatic VOC decomposition in air mixture by using electron beam irradiation," Radiation Physics and Chemistry, vol. 71, no. 1-2, pp. 435-438, 2004.

[104] A. G. Chmielewski, Y. Sun, S. Bułka, and Z. Zimek, "Review on gaseous chlorinated organics pollutants electron beam treatment," Radiation Physics and Chemistry, vol. 76, pp. 1795-1801, 2007.
[105] K. Hirota and T. Kojima, "Decomposition behavior of $\mathrm{PCDD} / \mathrm{F}$ isomers in incinerator gases under electron-beam irradiation," Bulletin of the Chemical Society of Japan, vol. 78, no. 9, pp. 1685-1690, 2005.

[106] H. Y. Jian, P. Zheng, Y. L. Sheng, et al., "Destruction of PCDD/Fs formed by pentachlorophenol via gliding arc discharges," Organohalogen Compounds, vol. 68, pp. 12471250, 2006.

[107] M. Nifuku, M. Horváth, J. Bodnár et al., "A study on the decomposition of volatile organic compounds by pulse corona," Journal of Electrostatics, vol. 40-41, pp. 687-692, 1997.

[108] D. Crespo and R. T. Yang, "Adsorption of organic vapors on single-walled carbon nanotubes," Industrial and Engineering Chemistry Research, vol. 45, no. 16, pp. 5524-5530, 2006.

[109] S. B. Fagan, E. J. G. Santos, A. G. Souza Filho, J. Mendes Filho, and A. Fazzio, "Ab initio study of 2,3,7,8-tetrachlorinated dibenzo-p-dioxin adsorption on single wall carbon nanotubes," Chemical Physics Letters, vol. 437, no. 1-3, pp. 79-82, 2007.

[110] R. T. Yang, R. Q. Long, J. Padin, A. Takahashi, and T. Takahashi, "Adsorbents for dioxins: a new technique for sorbent screening for low-volatile organics," Industrial and Engineering Chemistry Research, vol. 38, no. 7, pp. 2726-2731, 1999.

[111] R. Q. Long and R. T. Yang, "Carbon nanotubes as superior sorbent for dioxin removal," Journal of the American Chemical Society, vol. 123, no. 9, pp. 2058-2059, 2001.

[112] Y.-H. Shih and M.-S. Li, "Adsorption of selected volatile organic vapors on multiwall carbon nanotubes," Journal of Hazardous Materials, vol. 154, no. 1-3, pp. 21-28, 2008.

[113] J. Choi, O. Kim, and S.-Y. Kwak, "Suppression of dioxin emission in co-incineration of poly(vinyl chloride) with $\mathrm{TIO}_{2}$-encapsulating polystyrene," Environmental Science and Technology, vol. 41, no. 16, pp. 5833-5838, 2007.

[114] J. L. Graham, C. B. Almquist, S. Kumar, and S. Sidhu, "An investigation of nanostructured vanadia/titania catalysts for the oxidation of monochlorobenzene," Catalysis Today, vol. 88, no. 1-2, pp. 73-82, 2003.

[115] Y. Jiamg, S. Decker, C. Mohs, and K. J. Klabunde, "Catalytic solid state reactions on the surface of nanoscale metal oxide particles," Journal of Catalysis, vol. 180, no. 1, pp. 24-35, 1998.

[116] S. H. Kim, S.-Y. Ahn, and S.-Y. Kwak, "Suppression of dioxin emission in incineration of poly(vinyl chloride) (PVC) as hybridized with titanium dioxide nanoparticles," Applied Catalysis B, vol. 79, no. 3, pp. 296-305, 2008.

[117] P. S. Kulkarni, L. C. Branco, J. G. Crespo, and C. A. M. Afonso, "Capture of dioxins by ionic liquids," Environmental Science and Technology, vol. 42, no. 7, pp. 2570-2574, 2008.

[118] G. Fernández-Martínez, P. López-Mahía, S. MuniateguiLorenzo, D. Prada-Rodríguez, and E. Fernández-Fernández, "Distribution of volatile organic compounds during the combustion process in coal-fired power stations," Atmospheric Environment, vol. 35, no. 33, pp. 5823-5831, 2001.

[119] G. Fernández-Martínez, J. M. López-Vilariño, P. LópezMahía et al., "First assessment of dioxin emissions from coalfired power stations in Spain," Chemosphere, vol. 57, no. 1, pp. 67-71, 2004.

[120] C.-M. Chen, "The emission inventory of PCDD/PCDF in Taiwan," Chemosphere, vol. 54, no. 10, pp. 1413-1420, 2004.

[121] L.-F. Lin, W.-J. Lee, H.-W. Li, M.-S. Wang, and G.-P. Chang-Chien, "Characterization and inventory of PCDD/F 
emissions from coal-fired power plants and other sources in Taiwan," Chemosphere, vol. 68, no. 9, pp. 1642-1649, 2007.

[122] D. Herrmann and R. Herzschuh, "Formation of PCDD/F during thermal treatment of lignite," Journal of Analytical and Applied Pyrolysis, vol. 49, no. 1, pp. 211-220, 1999.

[123] O. Schleicher, A. Jensen, T. Herrmann, O. Roots, and A. Tordik, "Dioxin emission from two oil shale fired power plants in Estonia," Organohalogen Compounds, vol. 66, pp. 1635-1641, 2004.

[124] A. Grochowalski and J. Konieczyński, "PCDDs/PCDFs, dlPCBs and HCB in the flue gas from coal fired CFB boilers," Chemosphere, vol. 73, no. 1, pp. 97-103, 2008.

[125] E. Aries, D. R. Anderson, N. Ordsmith, K. Hall, and R. Fisher, "Development and validation of a method for analysis of " dioxin-like" PCBs in environmental samples from the steel industry," Chemosphere, vol. 54, no. 1, pp. 23-31, 2004.

[126] L.-C. Wang, W.-J. Lee, P.-J. Tsai, W.-S. Lee, and G.-P. ChangChien, "Emissions of polychlorinated dibenzo-p-dioxins and dibenzofurans from stack flue gases of sinter plants," Chemosphere, vol. 50, no. 9, pp. 1123-1129, 2003.

[127] H. C. Kai, H. C. Shu, and B. C. Moo, "PCDD/F emissions and distributions in Waelz plant and ambient air during different operating stages," Environmental Science and Technology, vol. 41, no. 7, pp. 2515-2522, 2007.

[128] H.-W. Li, W.-J. Lee, K.-L. Huang, and G.-P. Chang-Chien, "Effect of raw materials on emissions of polychlorinated dibenzo-p-dioxins and dibenzofurans from the stack flue gases of secondary aluminum smelters," Journal of Hazardous Materials, vol. 147, no. 3, pp. 776-784, 2007.

[129] T. Öberg, "Low-temperature formation and degradation of chlorinated benzenes, PCDD and PCDF in dust from steel production," The Science of the Total Environment, vol. 382, no. 1, pp. 153-158, 2007.

[130] European Parliament and the Council Directive 2000/76/EC of 4 December 2000 on the incineration of waste. - OJ No L 196, p. $1,2000 / 12 / 10$. 

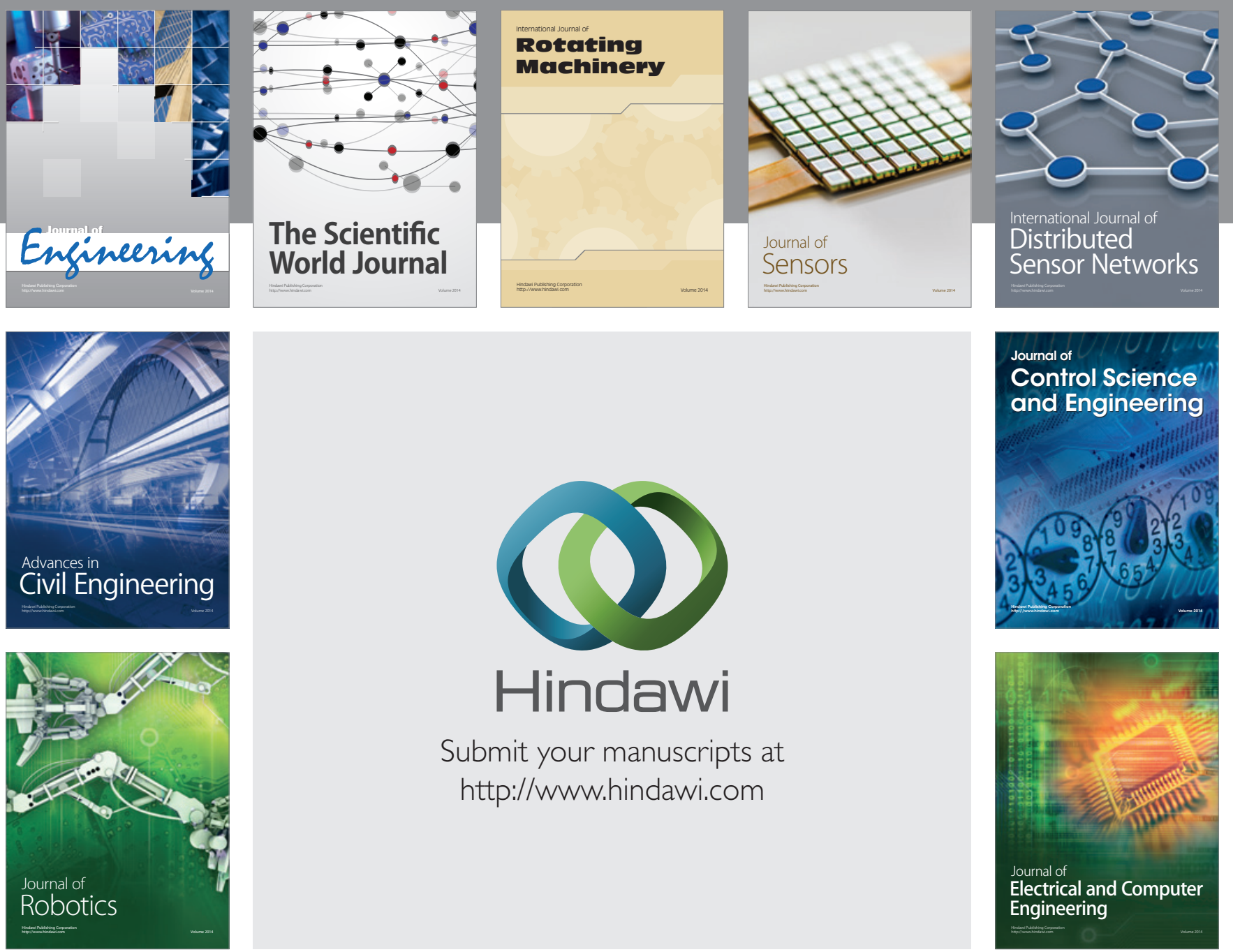

Submit your manuscripts at

http://www.hindawi.com
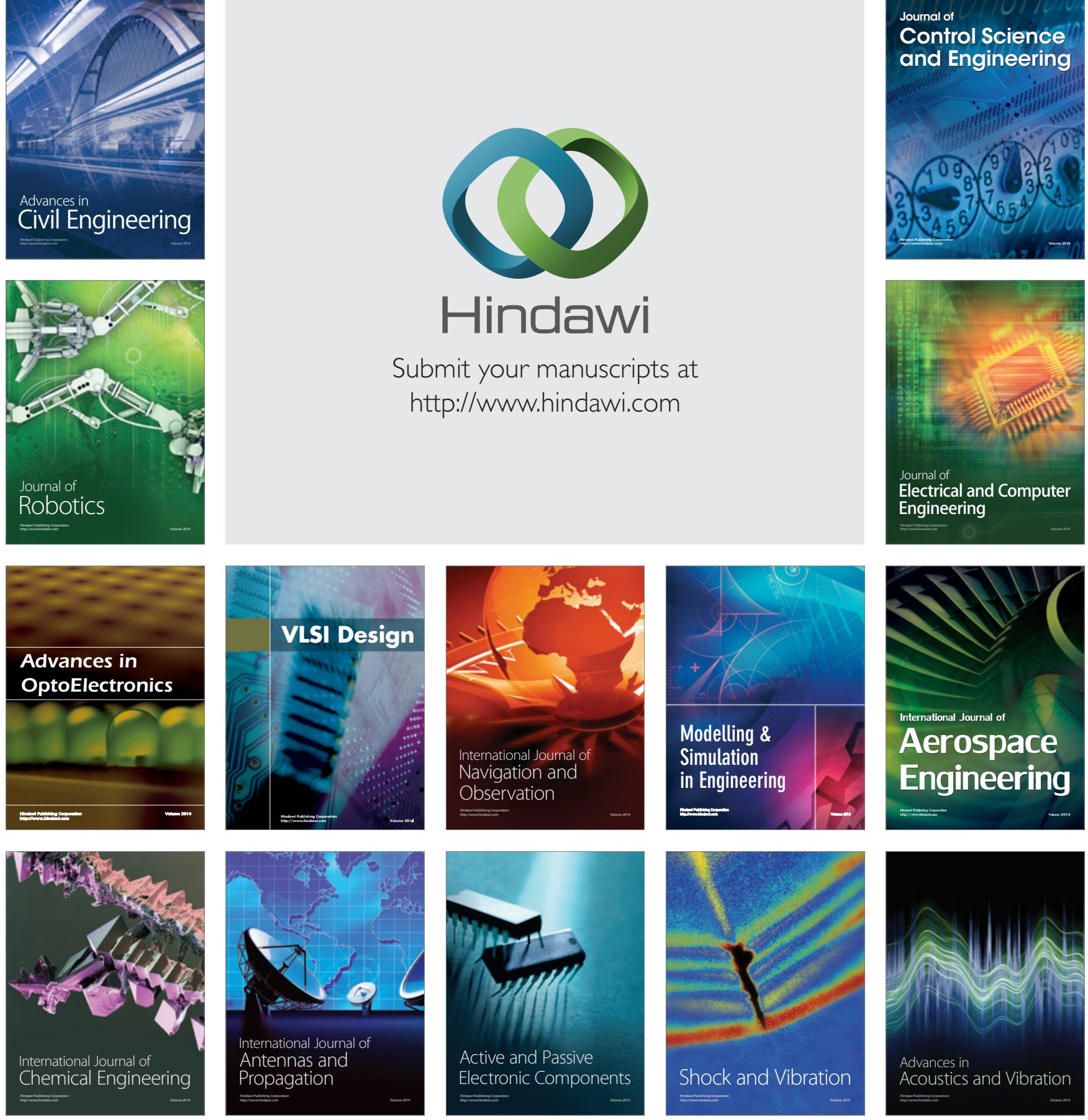